\title{
Uncovering Saudi English Language Majors' Cognitive Beliefs about Learning English Literature
}

\author{
Ayman Sabry Daif-Allah ${ }^{1} \&$ Fahad Hamad Aljumah ${ }^{2}$ \\ ${ }^{1}$ Professor of Applied Linguistics, Department of English Language and Translation, College of Arabic \\ Language and Social Studies, Qassim University, Saudi Arabia \& Arish University, Egypt \\ ${ }^{2}$ Associate Professor of Applied Linguistics, Department of English Language and Translation, College of \\ Arabic Language and Social Studies, Qassim University, Saudi Arabia \\ Correspondence: Ayman Sabry Daif-Allah, Professor of Applied Linguistics, Department of English Language \\ and Translation, College of Arabic Language and Social Studies, Qassim University, Saudi Arabia \& Arish \\ University, Egypt.
}

Received: February 25, 2020

Accepted: March 21, 2020

Online Published: March 28, 2020

doi: 10.5539/elt.v13n4p114

URL: https://doi.org/10.5539/elt.v13n4p114

\begin{abstract}
Evidence shows that learners' performance is largely influenced by their cognitive beliefs about learning. The main purpose of the present study is to identifying the cognitive beliefs of Saudi English Language major students in order to get a deeper insight into their inner thoughts about studying literature and to find out the effect of gender on deciding their preferences. A total of 71 male and female English language major Saudi students of the English Language and Translation Department in the Main Campus at Qassim University participated in the study. Data were collected quantitatively and qualitatively by means of students' questionnaires and interviews. Findings show that participants hold both motivating and demotivating/unrealistic cognitive beliefs about literature learning. The results provide valid evidence on the participants' informed awareness of the social and academic benefits of learning English literature and uncovered their supportive cognitive beliefs that might enhance willingness to study foreign literature. Likewise, it is revealed that issues related to difficulty of literature learning, classroom practices, curriculum and career opportunities have created the established demotivating cognitive beliefs underlying participants' disinclination to literature study. Results also show that analysis of learners' cognitive beliefs would help modify unrealistic beliefs about literature learning and help create a motivating learning environment suitable for the growth of students' knowledge. The study concluded that cognitive beliefs are the key word for the success of any educational development endeavors and should always be at the center of any learning process being the inner self human power that drives learners' major behaviors toward their learning preferences and choice of courses. The study recommends identification of learners' cognitive beliefs so as to provide guidelines to English literature instructors to tailor their teaching methods to learners' realistic cognitive beliefs to avoid mismatches with classroom practices. The study also recommends investigating the global structure of the students' cognitive beliefs to guide educationists in developing curricula that would help students acquire knowledge in an organized manner, and to improve it.
\end{abstract}

Keywords: cognitive beliefs, demotivation, literature, instrumental motivation, integrative motivation

\section{Introduction}

While language is the source of understanding, which differentiates one society apart from another, literature is the cradle of inspiration and expression of social, philosophical, religious, or whatever sort of ideas. Language is the means that carries the nation's heritage and its intellectual, literary and scientific achievements, while literature is the means to help to preserve language and the heritage and thought it carries. Moreover, the history of any language will be influential through the cautious and clever use of literature due to the fact that language and literature are inseparable, and studying one away from the other is a waste of time. Hussein \& Al-Emami (2016) argue that literature is the basis of language learning and that through literature, different cultures could be recognized. They emphasize that while language is the source of communication, literature is the medium of cultural transmission from generation to generation. Accordingly, literature is the heritage of any culture that can be revealed using a language. Literature is an expression of reality in aesthetic ways, dependent on language. In this context reality refers to the society with its cultural, economic and political components; with its movements 
and struggles; with its nature including mountains, rivers, plains, valleys and various geographical phenomena; with human beings including their conflicting desires, fears, fantasies and ideas that revolve in their mind are all manifested in their behaviors and activities. Therefore, the importance of literature literacy stems from the fact that it increases our understanding of societies and peoples' aspirations, and helps us in finding out what past civilizations and nations were like. For example, pre-Islamic literature and especially pre-Islamic poetry provides us with a lot of information about life in that era. Similarly, we can get to know the Arab community in Egypt by reading Naguib Mahfouz's novels, and get to know Paris and French society in the nineteenth century by reading the novels of the French writer Honoré de Balzac.

\subsection{Context of the Problem}

Saudi Arabia has recognized the importance of English literature learning long time ago as a carrier of other peoples' cultures, customs, history and values. In recent times, literature has become a major component and a cornerstone of that specialty with its relevant courses and research projects in more than one hundred and fifty English Language and Translation Departments in different Saudi universities. Qassim University has thirteen of those departments in different sites offering two major tracks namely: Linguistics \& Translation and Linguistics \& Literature. Although the mission statement of these departments reflect the importance of both tracks explicitly "Provide developed and accredited education to qualify competencies in English language, literature and translation, and offer community and research services to improve the local community and meet the needs of the labor market", yet the Linguistics \& Literature Track has been inactive since its beginning thirteen years ago due to students' reluctance for registration.

Therefore, the present researchers felt the need to have a clear understanding of the students' demotivational reasons and cognitive beliefs that underlie their unwillingness and disinclination to study a very important language component. It is the researchers' belief that learners with realistic and knowledgeable beliefs are more likely to perform effectively in the class, work harder outside the class, and persevere longer with language study. In line with this view, Schommer \& Easter (2017) and Abahussain (2016) noted that Cognitive beliefs have a major impact on students 'learning. The more we understand cognitive beliefs, the more we can provide better learning for students and adjusting education to suit their thinking. Borg (2017) points out that the uncovering students' beliefs can take us from the bottleneck as beliefs could be the password to better learning. Alghanmi \& Shukri (2016) add that Beliefs are the engine and the dynamo that sharpens energy and lights the way toward effective educational process.

Due to the researchers' experience, one of them is an ex-chairperson for the English Language and Translation Department and the second is a faculty in the same department, they observed that students are much more willing to study linguistics \& translation than linguistics \& literature. Results of the pilot study revealed that students believe that studying literature is too difficult, requires much memorization, the failure rate is high and job opportunities are too limited. These beliefs stand as the main cognitive challenges and barriers which prevent learners from studying an important branch of the English language. There are numerous studies that have addressed learners' beliefs worldwide in general and in the Saudi context in particular (Alharbi, 2019; Lieb, 2019; Abahussain, 2016; Al-Nasser, 2015; Alsalmi, 2014; Batawi, 2007). However, the topic of cognitive beliefs and its effects on English literature learning has not been sufficiently studied and has not been yet fully discovered.

\subsection{Problem of the Study}

The current research problem is determined by the identification of the cognitive beliefs of English language major students about studying English literature and the extent of the need for uncovering those beliefs among university students of different gender.

\subsection{Research Questions}

1. What are the cognitive beliefs of Saudi English Language major students about studying English literature?

2. What are the cognitive beliefs that hinder learners' willingness to study English literature?

3. To what extent does gender affect students' cognitive beliefs about studying literature?

\subsection{Hypotheses of the Study}

The present study seeks to examine the validity of the following hypotheses:

1. Saudi English Language major students hold motivating and demotivating cognitive beliefs about English literature learning. 
2. There are significant gender differences in cognitive beliefs about English literature learning among Saudi English Language major students.

\subsection{Objectives of the Study}

The current research aims to:

1. Provide a theoretical background on cognitive beliefs as a fundamental variable affecting English literature learning.

2. Identify the cognitive beliefs of Saudi English Language major students in order to get a deeper insight into their internal assumptions that controls and directs their behaviors toward their learning preferences and choice of courses and therefore influences academic achievement.

3. Study the effect of gender on the cognitive beliefs of Saudi English Language major students.

4. Shed light on the importance of cognitive beliefs to help create a motivating learning environment suitable for the growth of students' knowledge.

5. Provide information and data on cognitive beliefs that might help researchers do more research in this field to improve the educational process in English Language departments.

\subsection{Significance of the Study}

The present study is important for some reasons:

1. Analysis of cognitive beliefs is important for Saudi English Language major students since their academic preferences and performance are influenced by their beliefs of motivators and difficulties.

2. The study examines a universal research area in cognitive beliefs largely investigated by applied linguists.

3. The study provides information about the realistic and unrealistic cognitive beliefs of male and female Saudi English Language major students.

4. Identification of learners' assumptions will help literature instructors understand learners' expectations and the kind of goals they aspire to achieve through language learning.

5. The study will provide recommendations to EFL instructors to re-adjust the literature curriculum and modify their teaching strategies to meet learners' needs.

6. The study of cognitive beliefs guides policy makers to modifying education in a way that suits students' ways of thinking.

7. Knowing the global structure of the students' beliefs would guide educationists to develop curricula that help students to acquire knowledge in an organized manner and to improve it.

\subsection{Review of Literature}

In this digest, relevant theory and research are presented to provide a conceptual framework for the study.

\subsubsection{The Influence of Literature on English Language Learning}

English literature is defined as literature written in the English language, which reflects the culture of Western society, (Zengin \& Yükselir 2019). It is a mirror of the people and the society, and it has a taste for the etiquette of others, in addition to the artistic and aesthetic pleasure. Kaya (2018) reports that literature at its origin is a form of art that includes poetry, prose, novels, stories or other arts, and it is able to arouse overwhelming emotions and evoke emotions and spiritual sensations. Literature allows people to think in different ways, to create new ideas, and to define different views of the world, people and life. Literature is also useful in the process of learning the general and private customs and traditions of a society and individuals. At the educational level, Khatib \& Shakouri (2013) believe that English Literature can serve as the source of correlation between the students` proficiency and language use. Relevantly, Hussein \& Al-Emami (2016) explain that both language and literature are interrelated parts of English, and each is described as one side of a coin. Both are promoting people's communications and activities. While language is the system of communication used to express different thoughts, different types of literature affect language acquisition in accordance with culture, society, and area. In this context, Bobkina \& Dominguez (2014) state that reading and studying a novel, a play, or a poem in the target language would help in introducing learners to the culture through which that language passed. It is through reading a literary work written in a certain dialect of a language that a student may be aware of the varieties of that language (Zaker,2016). Literature classes, as Lieb (2019) puts it, help students find their voice. In this way, getting students talk in another language and providing them with opportunities for expressing 
themselves freely have a lot in common. Literature can be a tool rather than an end in teaching English as a second or foreign language (Cirakli \& Kilickaya, 2011). Likewise, reading works of different literary genres offers students familiarity with many various linguistic forms, communicative functions and meanings. Isikli \& Tarakcioglu (2017) claim that the study of literature enhances learners' writing skill since critical ideas need a good command of language for overflow of written expression. Furthermore, using literature also brings about the learners' personal involvement in interactive and fruitful discussions with fellow classmates and the instructor. That is, they begin to react emotionally to the story that is being unfolded, which has a beneficial effect on the whole language-learning process.

\subsubsection{Definition of Cognitive Beliefs}

Knowledge and beliefs are inseparably intertwined. Knowledge can be defined as information or awareness gained through experience or education and it arises from a specific set of data related to any given field. It is not based on the thoughts of the individual as in the case of belief but is based on data. Beliefs are a long time in the making and can go virtually unnoticed. They are firm opinions and strong determiners of individuals' thoughts and behaviors (Ramshe et al., 2019). A belief is an individual cognitive act or state in which a proposition is taken to be true and it revolves around certain principles based on subjective experience and stems from the inner individual's conviction. Accordingly, cognitive beliefs are viewed as a mental system consisting of interconnected items of ideas, knowledge and assumptions that students hold about themselves as learners, about factors influencing language learning, and about the nature of language learning and teaching (Alrabai, 2014). Beliefs as such are viewed as predictors of outcome variables such as achievement, comprehension, and conceptual change. (Hofer, 2004). In other words, students with more enhanced beliefs will be more likely to keep active inquiry and persist in looking for right information and knowledge, to integrate information, and to handle ill-structured domains and problems.

\subsubsection{The Role of Learners' Cognitive Beliefs in Learning Performance}

Kaşlığlu \& Ersin (2018) found that learners' cognitive beliefs have a significant impact on learning behavior and learning performance. Bernat (2008) argues that learners' beliefs have a strong powerful force in academic performance. Learners may be directly influenced by their awareness of success in learning and the levels of expectation with persuasively high prospects helping them to build their confidence, while low expectations lead to demotivation and disappointment (Alghanmi \& Shukri,2016). It has been argued that while some beliefs may have a positive effect on learning, others can challenge it. Supportive beliefs help to solve academic problems and thus enhance motivation, whereas demotivating beliefs can lead to frustration, and even failure (Massri,2019). The results of Alharbi (2019), Yang (2018), Abahussain (2016) and Horwitz (1988) found close correlation between learners' cognitive beliefs, and the types of strategy use and final achievement in language acquisition. Spataro et al., (2018), Al-Nasser (2015) and Alsalmi (2014) suggested that a mismatch between teacher and learner beliefs can lead to reduced learner satisfaction with the class and to reluctance to contribute in communicative tasks. In line with these studies, Daif-Allah (2012) concluded that identification of learners' beliefs is fundamental for effective EFL classroom education.

Through the previous studies discussed above, it is clear that more research is needed to investigate cognitive beliefs about foreign literature learning. Accordingly, this study tries to identify the English language major female/male university learners' cognitive beliefs about studying the English language literature and to explore the impact of gender differences on those beliefs.

\section{Methods}

\subsection{Participants}

English language major advanced level students of the English Language and Translation Department in the Main Campus at Qassim University participated in the study. The students were given a brief orientation of the aims of the study before the questionnaire administration. A total of 71 English language major high level students were randomly selected to respond to the questionnaire items and to participate in the interview. These students were at the $7^{\text {th }}$ and $8^{\text {th }}$ levels, 35 were males $(51 \%)$ and 36 were females $(49 \%)$. The mean age of the participants was 21.4 years, rating from 20-22 years. The students' average experience in studying English in the English Language \& Translation Department was 3.5-4 years. The students included in this study share important common features with most English language major students in Saudi Arabia. They all belong to government university, they all belong to the same education system, and they follow the same curricula. 


\subsection{Instruments}

Based on the previous review of literature, data were collected quantitatively and qualitatively using questionnaires and interviews with English language majors.

\subsubsection{The Questionnaire}

The questionnaire is divided into two parts. The first part aims to gather information concerning students' background information such as gender, academic level and age. The second part addresses students' cognitive beliefs about learning English literature. It consists of 37-items categorized into six domains: 1- Difficulties of Studying Literature (7 items); 2- Friendship (4 items); 3- Education (7 items); 4- Employment (5 items); 5Internet (4 items) and, 6- Enjoyment (10 items). The questionnaire is based on five point Likert scale measuring participants' interest according to their level of agreement or disagreement. It was developed and adapted from various related sources (Alharbi, 2019; Abahussain, 2016; Al-Nasser, 2015; Daif-Allah, 2012; Altan, 2012; Buyukyazi, 2012 and Horwitz, 2007\&1988). It was administered electronically in English so that students would understand and answer items easily and their responses would reflect their true beliefs. To assess the level of reliability of the questionnaire, a pilot administration was conducted on five male and five female students. The feedback from the pre-administration showed that the questionnaire was completely appropriate for research aims. Also Cronbach alpha of this study is 0.74 which shows acceptable consistency of reliability.

\subsubsection{The Interview}

The interview is meant to confirm and complement information gathered from the questionnaire. A total of 71 male and female students in the 7th and 8th levels participated in the interview which utilized open-ended questions. The interviewees were given the choice of using English or Arabic for expressing their views.

\section{Results and Discussion}

\subsection{Questionnaire Results}

\subsubsection{Analysis of Students' Cognitive Beliefs about Learning English Literature}

The main purpose of the present study is to explore the cognitive beliefs of Saudi English Language major students in order to get a deeper insight into their minds. Data gleaned from the questionnaires were analyzed in light of response frequencies, and the results were given as percentages as shown in table 1 below. Two positively worded points (agree and strongly agree) and two negatively worded points (disagree and strongly disagree) were combined together so that the respondents supportive or passive beliefs on one item could be measured. Since no gender differences were found in learners' responses as will be shown in Table 2 and figure 1 , Mean of total percentages was used in describing and discussing results.

Table 1. Analysis of students' cognitive beliefs about learning English literature

\begin{tabular}{|c|c|c|c|c|c|c|c|c|c|c|}
\hline \multirow[b]{2}{*}{ Questionnaire Domains \& Items } & \multicolumn{4}{|c|}{ Females } & \multicolumn{3}{|c|}{ Males } & \multicolumn{3}{|c|}{ Total } \\
\hline & $\frac{\vec{g}}{8}$ & 官 & 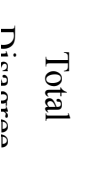 & 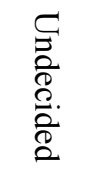 & $\stackrel{\overrightarrow{0}}{\vec{D}}$ & 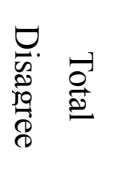 & 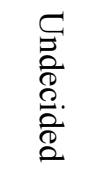 & 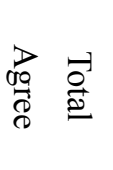 & 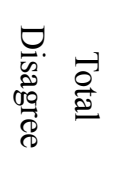 & $\begin{array}{l}c \\
\stackrel{2}{0} \\
\frac{1}{2} \\
\frac{0}{2} \\
\frac{2}{2}\end{array}$ \\
\hline Domain one: Difficulties of Studying Literature & $\%$ & & $\%$ & $\%$ & $\%$ & $\%$ & $\%$ & $\%$ & $\%$ & $\%$ \\
\hline $\begin{array}{l}\text { Linguistics \& Translation is easier than } \\
\text { Linguistics \&Literature. }\end{array}$ & & $92 \%$ & $3 \%$ & $6 \%$ & $89 \%$ & $0 \%$ & $11 \%$ & $91 \%$ & $2 \%$ & $9 \%$ \\
\hline g literature requires much memorization. & & $89 \%$ & $3 \%$ & $8 \%$ & $63 \%$ & $17 \%$ & $20 \%$ & $76 \%$ & $10 \%$ & $14 \%$ \\
\hline $\begin{array}{l}\text { iterary texts written in Old English are difficult } \\
\text { stand. }\end{array}$ & & $94 \%$ & $3 \%$ & $3 \%$ & $83 \%$ & $6 \%$ & $11 \%$ & $89 \%$ & $5 \%$ & $6 \%$ \\
\hline $\begin{array}{l}\text { ure rate in literature courses is higher than } \\
n \text { other courses. }\end{array}$ & & $81 \%$ & $3 \%$ & $17 \%$ & $69 \%$ & $17 \%$ & $14 \%$ & $75 \%$ & $10 \%$ & $15 \%$ \\
\hline $\begin{array}{l}\text { g literature Require a high level of language } \\
\text { ncy. }\end{array}$ & & $92 \%$ & $3 \%$ & $6 \%$ & $77 \%$ & $9 \%$ & $14 \%$ & $84 \%$ & $6 \%$ & $10 \%$ \\
\hline $\begin{array}{l}\text { uistic and stylistic degree of the literary texts } \\
\text { cult. }\end{array}$ & & $94 \%$ & $3 \%$ & $3 \%$ & $89 \%$ & $11 \%$ & $0 \%$ & $92 \%$ & $6 \%$ & $2 \%$ \\
\hline (un)familiarity is a challenge to studying & & $83 \%$ & $6 \%$ & $11 \%$ & $77 \%$ & $6 \%$ & $17 \%$ & $80 \%$ & $6 \%$ & $14 \%$ \\
\hline
\end{tabular}


literature

Domain two: Friendship

8- Learning English literature will help me to better understand English-speaking people through avoiding stereotypes.

9- Learning English literature will help me discuss English literature issues with native speakers.

10- Learning English literature will encourage me to improve my knowledge of English way of life.

11- Learning English literature will help me appreciate other cultures and beliefs.

\section{Domain three: Education}

12- Learning English literature will develop my English Language proficiency.

13- Learning English literature will be an asset to linguistic competence development.

14- Learning English literature will allow me to do well in ESL local / international proficiency tests.

15- Learning English literature is an excellent part of the curriculum.

16- Learning English literature will allow me to pursue high-level study at the graduate level abroad.

$\begin{array}{rrrrrrrrr}86 \% & 6 \% & 8 \% & 71 \% & 6 \% & 23 \% & 79 \% & 5 \% & 16 \% \\ 78 \% & 8 \% & 14 \% & 66 \% & 11 \% & 23 \% & 72 \% & 9 \% & 19 \% \\ 81 \% & 3 \% & 17 \% & 43 \% & 14 \% & 43 \% & 62 \% & 9 \% & 29 \% \\ 92 \% & 3 \% & 6 \% & 77 \% & 9 \% & 14 \% & 84 \% & 6 \% & 10 \%\end{array}$

7- English literature will enable me to be informed about the attitudes of other countries towards Saudi people.

$\begin{array}{rrrrrrrrr}94 \% & 3 \% & 3 \% & 83 \% & 6 \% & 11 \% & 89 \% & 5 \% & 6 \% \\ 89 \% & 3 \% & 8 \% & 63 \% & 9 \% & 29 \% & 76 \% & 6 \% & 18 \% \\ 92 \% & 3 \% & 6 \% & 63 \% & 17 \% & 20 \% & 78 \% & 10 \% & 12 \% \\ 6 \% & 6 \% & 89 \% & 14 \% & 29 \% & 57 \% & 10 \% & 17 \% & 73 \% \\ 92 \% & 6 \% & 3 \% & 66 \% & 14 \% & 20 \% & 79 \% & 10 \% & 11 \% \\ 83 \% & 6 \% & 11 \% & 69 \% & 3 \% & 29 \% & 76 \% & 5 \% & 19 \% \\ 86 \% & 3 \% & 11 \% & 54 \% & 9 \% & 37 \% & 70 \% & 6 \% & 24 \%\end{array}$

18- Learning English literature will enable me to get an EFL qualification in the English literature track.

Domain four: Employment Opportunities

19- Learning English literature is a requirement in most good jobs.

$\begin{array}{lllllllll}3 \% & 94 \% & 3 \% & 14 \% & 57 \% & 29 \% & 9 \% & 75 \% & 16 \% \\ 8 \% & 86 \% & 6 \% & 14 \% & 69 \% & 17 \% & 11 \% & 78 \% & 11 \% \\ 6 \% & 83 \% & 11 \% & 6 \% & 60 \% & 34 \% & 6 \% & 72 \% & 22 \% \\ 3 \% & 86 \% & 11 \% & 9 \% & 71 \% & 20 \% & 6 \% & 79 \% & 16 \% \\ 6 \% & 89 \% & 6 \% & 7 \% & 80 \% & 13 \% & 5 \% & 85 \% & 10 \%\end{array}$

20- People who know English literature will have a better chance in getting a high-pay job.

21- English literature will allow me to develop new job ideas.

22- English Language literature graduates will have better job opportunities than linguistics and translation graduates.

23- English literature will help me develop critical thinking skills that are essential for today's global job environment

\section{Domain five: Internet}

24- Learning English literature will help me to use the Internet better.

25- English literature will give me a chance to chat with English native speakers about different cultural topics.

26- English literature will enable me to communicate ideas about religion through the Internet.

27- English literature will allow me to talk about my country through the Internet.

$\begin{array}{rrrrrrrrr}89 \% & 6 \% & 6 \% & 54 \% & 23 \% & 23 \% & 72 \% & 14 \% & 14 \% \\ 94 \% & 3 \% & 3 \% & 77 \% & 6 \% & 17 \% & 86 \% & 5 \% & 9 \% \\ 89 \% & 0 \% & 11 \% & 57 \% & 9 \% & 34 \% & 73 \% & 5 \% & 22 \% \\ 81 \% & 8 \% & 11 \% & 66 \% & 11 \% & 23 \% & 74 \% & 10 \% & 16 \%\end{array}$


Domain six: Enjoyment

28- English literature will help me get along with native speakers of English when visiting their countries.

29- English literature will enable me to follow TV English programs and films.

30- English literature will give me a chance to read English magazines and newspapers.

31- English literature will develop my cross-culture awareness.

32- English literature is a great tool to approach the English language culture.

33- English literature will present me as an educated member of society.

34- The history of any language is powerful through the careful and clever use of literature.

35- English literature is the source of inspiration and expression of social life.

36- English literature is an enriching, eye-opening experience.

37- Learning English literature will enable me to enjoy reading literary texts.

\begin{tabular}{|c|c|c|c|c|c|c|c|c|}
\hline $89 \%$ & $0 \%$ & $11 \%$ & $69 \%$ & $11 \%$ & $20 \%$ & $79 \%$ & $5 \%$ & $16 \%$ \\
\hline $89 \%$ & $0 \%$ & $11 \%$ & $66 \%$ & $11 \%$ & $23 \%$ & $78 \%$ & $5 \%$ & $17 \%$ \\
\hline $92 \%$ & $3 \%$ & $6 \%$ & $63 \%$ & $11 \%$ & $26 \%$ & $78 \%$ & $6 \%$ & $16 \%$ \\
\hline $92 \%$ & $3 \%$ & $6 \%$ & $69 \%$ & $6 \%$ & $26 \%$ & $81 \%$ & $5 \%$ & $14 \%$ \\
\hline $83 \%$ & $3 \%$ & $14 \%$ & $74 \%$ & $3 \%$ & $23 \%$ & $79 \%$ & $3 \%$ & $18 \%$ \\
\hline $94 \%$ & $3 \%$ & $3 \%$ & $60 \%$ & $11 \%$ & $29 \%$ & $77 \%$ & $7 \%$ & $16 \%$ \\
\hline $86 \%$ & $6 \%$ & $8 \%$ & $63 \%$ & $9 \%$ & $29 \%$ & $75 \%$ & $8 \%$ & $18 \%$ \\
\hline $86 \%$ & $3 \%$ & $11 \%$ & $60 \%$ & $9 \%$ & $31 \%$ & $73 \%$ & $5 \%$ & $22 \%$ \\
\hline $89 \%$ & $3 \%$ & $8 \%$ & $69 \%$ & $9 \%$ & $23 \%$ & $79 \%$ & $5 \%$ & $16 \%$ \\
\hline $89 \%$ & $3 \%$ & $8 \%$ & $69 \%$ & $17 \%$ & $14 \%$ & $79 \%$ & $9 \%$ & $12 \%$ \\
\hline
\end{tabular}

The results presented in Table 1 above uncovers the general assumptions students hold about themselves as learners, about the nature of literature learning, and about factors influencing their willingness to register in the Linguistics \& Literature Track. The results in the above table show the participants' supportive as well as passive cognitive beliefs about learning English literature and accordingly provides the answer to the first research question "What are the cognitive beliefs of Saudi English Language major students about studying English literature?". Learners beliefs about the difficulties of studying literature and employment opportunities are the main challenges responsible for disinclination to study the English literature. The first domain items 1-7 "Difficulties of Studying Literature" and the fourth domain items 19-23 “Employment Opportunities" reveal the common challenges hindering students' willingness to study the English literature. However, the participants' responses to the other domains of "friendship" items 8-11, “education" items 12-18, "the internet" items 24-27 and "enjoyment" items 28-37 underlie their positive and realistic beliefs about learning English literature.

The first domain "Difficulties of Studying Literature" came to reveal the major cognitive beliefs responsible for students' disinclination to learning English literature. The majority of the students (91\%) considered that studying Linguistics \& Literature is more difficult than studying Linguistics \& Translation for the simple reason that the earlier requires more memorization and a high level of language proficiency. Learners had an inner conviction that the linguistic and stylistic degree of the literary texts are difficult to understand specially some literary texts are written in old English that is difficult for even some native speakers. This belief represented a barrier demotivating participants to register in the Linguistics \& Literature Track as seen by $92 \%$ of the subjects of the study. In addition, lack of cross cultural awareness was an obstacle to studying literature as seen by $80 \%$ of the sample. Results of this domain are consistent with those of Alsumait, (2015); Barvarz\& Ahmadi (2014); El-Helou (2010), Marzooghi \& Shemshiri (2008), Trautwein \& Ludtke (2007), Schommer \& Easter (2006) and Cano (2005) who attributed the first two difficulties to inappropriate methods used in the process of teaching literature and the students' concentration on memorization as a strategy for learning. This approach aims at making students dependent on rote learning, which is an appropriate strategy for the kinds of exams for which they are supposed to be sitting. Since tests favour memorization over understanding and creativity, teachers in most cases focus on just helping students memorize some content points and some grammatical structures. These reasons create negative cognitive beliefs which in turn are responsible for learners' development of some psychological barriers. The other difficulties could be ascribed to learners' insufficient knowledge of the aims 
and objectives for studying literature, learners 'concentration on the content and unawareness of the language skills embedded in literary texts, absence of proper academic guidance that shows learners how to use the appropriate strategies for studying literature, and lack of academic orientations offered to learners to enhance their background knowledge of the benefits of literature learning. Additionally, weakness in English language skills would make getting the real meaning of the literary texts difficult as some quotations are written in a language which is different from everyday English.

The fourth domain items 19-23 "Employment Opportunities" uncovered another key type of negative cognitive beliefs affecting learners' willingness to study English literature. This domain addresses beliefs about lack of career opportunities available for Linguistics \& Literature Track graduates. Learners expressed firm opinions and strong thoughts regarding the insignificance of literature learning as a means of getting a job. They believe that there is no benefit of studying literature as it is not a requirement in many good jobs. In this regard, instrumental motivation seems to have a considerable impact on deciding their learning preferences and finding a good job upon completion of their study. $75 \%$ of the participants believe that learning English literature is not a requirement in many good jobs and that people who know linguistics \& literature will not be privileged to have a better chance in getting a high-pay job than linguistics \& translation graduates as seen by $79 \%$ of them. English literature was not considered as effective on developing critical thinking skills that are essential for today's global job environment as seen by $85 \%$ of the participants. In addition, $72 \%$ of the participants think that learning English literature doesn't have a significant effect on developing new job ideas. These results are in line with Carolina \& Morrison (2019), Ramshe et al. (2019), Ramshe (2018), Schommer \& Easter (2017) and Abahussain (2016) who found that beliefs about the economic gains of higher education have a considerable impact on learners' academic choices. In the present study, economic reasons are verified as burdensome and challenges affecting learners' willingness to learning literature.

However, these cognitive beliefs are subjective and unrealistic as they do not necessarily reflect external reality about the value of learning English literature. They just reflect the psychologically held understandings, individual premises, or propositions that participants of the study hold about the learning of English literature and that are felt to be true. These participants might not have enough knowledge about the correctness of the validity of their viewpoints, but they absolutely feel confident to act upon, and they accept them as true, although these may be questioned in the future. This idea corresponds to Sakui and Gaies (1998) who concluded that beliefs are subjective understandings, are relatively stable and are idiosyncratic. In addition, Zengin \& Yükselir (2019) point out that literature inspires learners to think over tender or beautiful features of life and enhances their vocabulary and improves their sense of literary appreciation. Kaya (2018), and Khatib \& Shakouri (2013) confirm that learners who do not know the aims of studying literature are likely to lose the sense of pleasure and enjoyment that goes with the study of literature. Accordingly, analysis and discussion of the results gleaned from the first and fourth domains Difficulties of Studying Literature" and "Employment Opportunities" provide the answer to the second research question "What are the cognitive beliefs that hinder learners' willingness to study English literature?"

On the other hand, the participants' responses to the other domains of "friendship", “education", "the internet" and "enjoyment" reflect high level of optimistic and realistic beliefs about the importance of learning English literature, and, therefore, are potentially facilitative for learners to studying literature. Friendship is a supportive domain underlying learners' inclination toward studying literature. Participants of the study seem to hold a high level of integrative motivation and strong willingness to learn about the English speaking people ways of life since $84 \%$ of them realize the value of studying English literature as a means for enhancing tolerance and appreciation of other peoples' cultures and beliefs. The participants also understand that learning English literature will encourage them to improve their knowledge of foreign people lifestyles and promote cross- culture communication as seen by $79 \%$ of them. In addition, participants are aware that stereotypes and communication breakdown result due to lack of cross-culture awareness.

The Education domain is another supportive factor instrumentally motivating participants to learning foreign literature. Participants of the study were selected from among advanced level students so that they have enough experience to estimate the educational benefits of studying English literature as an important part of the curriculum. Their responses to the Education Domain items came to reflect their realistic beliefs about the role of learning English literature on enhancing their language proficiency. $89 \%$ of the participants are confident that learning English literature would develop their linguistic competence in general and English Language proficiency in particular. Learning English literature is viewed by $76 \%$ of the participants as an asset to allow them to do well in ESL local / international proficiency tests. The cognitive beliefs that the participants of the study have would guide their intentions and actions. This is quite evident in their beliefs that English literature 
will enable them to be informed about the attitudes of other countries towards Saudi people, and will allow them to pursue high-level of study at the graduate level abroad, as seen by $79 \%$ of the sample. Whereas $10 \%$ of the participants considered learning English literature as an excellent part of the curriculum, only $17 \%$ declined it and the majority were undecided. The researchers attributed this finding to lack of informed orientations offered to English language majors about the fundamental role of literature in language acquisition. This role was unclear to $73 \%$ of the participants.

The Internet and Enjoyment Domains provide evidence of the decisive role cognitive beliefs play in learning English literature. $86 \%$ of the sample have realistic beliefs that English literature will give them a chance to chat with English native speakers about different cultural topics, to communicate ideas about religion $(73 \%)$ and to talk about their country (74\%) through the internet. Participants' responses to items of the Enjoyment Domain indicate that learners who perceive their studies as interesting show higher degrees of persistence in their study. The responses also show that learners are integratively motivated toward learning English literature as they have the inner belief that English literature is the source of inspiration and expression of social life, and that the history of any language is powerful through the careful and clever use of literature as viewed by $73 \%$ of the participants. Students hold positive beliefs about learning literature as it will enable them to get along with native speakers of English when visiting their countries and to follow TV English programs and films (79\%), to read English magazines and newspapers and develop their cross-culture awareness $(81 \%)$, to present them as an educated member of society $(77 \%)$, and to enjoy reading literary texts $(79 \%)$. These results are consistent with those of Daif-Allah (2012) and Daif-Allah \& Aljumah (2020) who found that motivation is an important variable that shapes learners' idea about foreign language learning. In agreement with these results, Alshehri \& Etherington (2017) concluded that motivation is the heart of the learning process and unless learners are motivated in a way or another there will be no life in the class. Accordingly, the above discussion provides evidence for the validity of the first research hypothesis "Saudi English Language major students hold motivating and demotivating cognitive beliefs about English literature learning"

\subsubsection{Analysis of Gender Differences in Relation to Cognitive Beliefs about Learning English Literature}

Another aim for the present study was to find out gender differences in learners' cognitive beliefs about learning English literature. Towards this end, Mean and Standard Deviation of male and female participants' responses were calculated and compared to examine the situation.

Table 2. Analysis of Gender Differences in Cognitive Beliefs about Learning English Literature

\begin{tabular}{lcccccc}
\hline \multicolumn{1}{c}{ Domain } & \multicolumn{2}{c}{ Females } & \multicolumn{2}{c}{ Males } & \multicolumn{2}{c}{ Total } \\
& Mean & $\begin{array}{c}\text { Standard } \\
\text { Deviation }\end{array}$ & Mean & $\begin{array}{c}\text { Standard } \\
\text { Deviation }\end{array}$ & Mean & $\begin{array}{c}\text { Standard } \\
\text { Deviation }\end{array}$ \\
\hline Difficulties of Studying Literature & 2.82 & 0.10 & 2.66 & 0.15 & 2.74 & 0.13 \\
Friendship & 2.74 & 0.11 & 2.39 & 0.27 & 2.56 & 0.19 \\
Education & 2.60 & 0.62 & 2.30 & 0.36 & 2.45 & 0.49 \\
Employment & 1.98 & 0.04 & 1.87 & 0.10 & 1.93 & 0.07 \\
The Internet & 2.81 & 0.09 & 2.39 & 0.16 & 2.60 & 0.13 \\
Enjoyment & 2.81 & 0.07 & 2.42 & 0.09 & 2.62 & 0.08 \\
\hline
\end{tabular}

The above table shows that male and female mean responses are very close to each other and that they share similar cognitive beliefs in all the six domains. Although students in Saudi Arabia don't study in mixed classes and that female students study in different locations and mostly instructors are different, yet they came to agree on all the 37 items contained in the six domains of the questionnaires. One major reason for that, from the researchers' point of view, is the sharing of ideas and thoughts among males and females through the social media. They have made smart use of technology to enhance and reinforce academic discussions related to all areas of study starting from course objectives to exams. Interests, experiences, motivators, challenges, worries, expectations, job opportunities, preferences etc., are all shared among students of the same and/or different gender. This result provides the answer to the second research question "How does gender affect students' beliefs about studying literature? " and the following figure illustrates the similarity in male and female English language majors' cognitive beliefs. 
Gender differences in cognitive beliefs about learning English literature
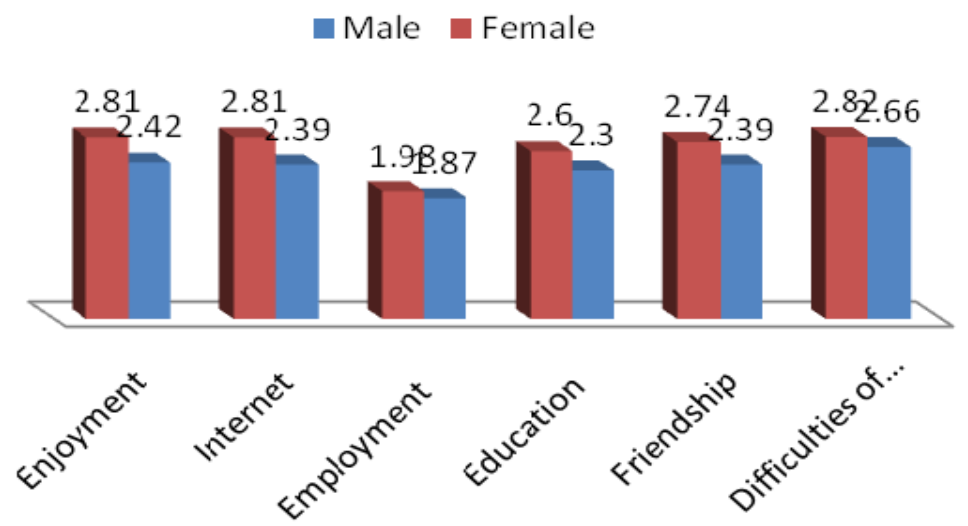

Figure 1. Gender differences in cognitive beliefs about learning English literature

In an attempt to find out if there are any significant gender differences in learners' cognitive beliefs about learning English and to test the validity of the second research hypothesis, additional results were gleaned by using the Wilcoxon- Mann-Whitney test as shown in Table 3 below.

Table 3. Significance of Gender differences in cognitive beliefs about learning English literature

\begin{tabular}{|c|c|c|c|c|}
\hline \multirow{2}{*}{ Domains } & \multicolumn{2}{|c|}{ Mean Rank } & \multirow{2}{*}{$\begin{array}{c}\text { Wilcoxon } \\
\text {-Mann-Whitney } U\end{array}$} & \multirow{2}{*}{$\begin{array}{l}\text { Asymp. Sig. } \\
\text { (2-tailed) }\end{array}$} \\
\hline & Females & Males & & \\
\hline Difficulties of Studying Literature & 115.34 & 119.04 & 6718.8 & 0.656 \\
\hline Friendship & 118.04 & 116.64 & 6853.8 & 0.871 \\
\hline Education & 116.08 & 118.38 & 6801.3 & 0.790 \\
\hline Employment & 122.71 & 112.5 & 6336.3 & 0.226 \\
\hline Internet & 121.89 & 113.22 & 6426.3 & 0.306 \\
\hline Enjoyment & 117.08 & 116.38 & 6805.3 & 0.661 \\
\hline
\end{tabular}

The above findings provide evidence that there are no significant differences between male and female participants' cognitive beliefs about studying English literature in all the six domains. They share similar cognitive beliefs and their motives and worries are very close. This last result disproves the validity of the second research hypothesis " There are significant gender differences in cognitive beliefs about English literature learning among Saudi English Language major students". The above findings disagree with Daif-Allah (2012) who found gender differences among Saudi male and female students' beliefs about foreign language learning. In addition, gender differences were also found among Iranian undergraduate students in epistemological beliefs of Also, (Marzooghi et al. 2008)

\subsection{Interview Results}

The interview is meant to confirm and complement information gathered from questionnaires. All the selected participants, 71 male and female students in the 7th and 8th levels, participated in the interview which utilized open-ended questions designed to reveal important information about their cognitive beliefs that motivate or demotivate studying literature. The interviewees were given the choice of using English or Arabic for expressing their views. Participants show awareness of the importance of literature learning as a means of understanding the history and culture of the English speaking people, expanding their knowledge of the world, critically building up their thinking skills, enhancing tolerance and appreciation of different cultures, and developing their English 
language proficiency. Students were also encouraged to communicate their thoughts and to explain why they are disinclined to study literature. Their responses were spontaneous and expressing true feelings. Some students admitted that they don't welcome literature study due to their weak EFL proficiency level that hiders them from dealing with literary texts that are hard and complicated to comprehend and fruitless at the end. For this reason, learners become frustrated and disappointed with the class and with themselves resulting in hindrance in the understanding of the material. Other student mentioned that they highly appreciate literature but they are unhappy with the methods of teaching. They explained that the lecture method makes them feel uptight with its implications for the exam as a demotivating factor that makes them take the study of the literary text as a difficult task to do rather than an entertaining one. In line with this result, Lieb (2019), and Zaker (2016) recommend using innovative teaching methods in literature classes that would include LCD, videos, films or using nonverbal language on the part of the instructor to help learners grasp the essence and true meaning of the literary text and to create good atmosphere for students and to facilitate the process of teaching literature. Likewise, Hussein \& Al-Emami (2016), Bobkina \& Dominguez (2014) and Cirakli \& Kilickaya (2011) suggest organizing English literature classes into small group formats to provide relaxed and interactive classroom learning environment. Participants also requested re-adjustment of the English literature curriculum so as to take into account students' real levels of EFL proficiency, and to review or reconsider it in such ways as to focus on developing both literary and linguistic competences. Students came to agree that in order to develop or gain confidence in the study of English literature, the instructors should build on the students' previous knowledge, linguistic competence, experience, and ideas about the literature course they study. In Saudi Arabia, students do not study English literature in high school or even in the first three semesters in college and therefore the participants recommended introducing preliminary literature courses in earlier levels and in high school as a way to overcome some of the challenges of foreign literature learning. In consistent with Alshehri \& Etherington (2017), participants also explained that most of the job ads are targeted to linguistics \& translation graduates and therefore they are worried about job opportunities that would be available for linguistics \& literature graduates.

\section{Conclusions and Recommendations}

In light of the theoretical background and the research findings it can be concluded that cognitive beliefs are the key word for the success of any educational development endeavors and should always be at the center of any learning process. Cognitive beliefs are the inner self human power that drives the individual learner's major behaviors toward their learning preferences and choice of courses and therefore influences academic achievement. Cognitive beliefs affect learners' judgments of their learning, the goals they seek to achieve, their choice of cognitive strategies, the forms of thinking they exercise, and the decisions they take. Thus, in the absence of careful identification of cognitive beliefs, instructors would be challenged to do their job properly because these beliefs have considerable effect on the success of their teaching task, as well as the outcome of the teaching that they do. Likewise, uncovering learners' cognitive beliefs and motivating tendencies would be useful in solving serious educational problems since match or mismatch between those beliefs, as individual influencing forces, and classroom practices determines the success or failure of the whole teaching/learning process. Learners' voices are always louder and should be heard. Accordingly, instructors need to listen to learners' opinions, delve deep to understand their inner thoughts and innate learning styles, find out about their preferences for the process of acquiring knowledge and correcting their unrealistic beliefs through approachable dialogues and informed orientations. There is also a need to have ongoing discussions with different employment agencies to keep them informed with the capabilities of literature graduates so as to correct stereotypes related to the linguistic proficiency of those qualities and to decide the job opportunities suitable for them. The study also recommends re-adjusting the English literature curriculum offered to all English language majors at the fourth level taking into account students' actual levels of proficiency, learning styles and preferences as ways as to prioritize both literary and linguistic competence development. In addition, classroom format and seating arrangement should be modified to encourage open discussions among learners. Although, the researchers are highly convinced that the literature instructor's role in modifying learners' tendencies toward literature study in not easy, yet s/he could play an effective role in breaking down the psychological barriers between learners and literature learning through creating a relaxed, interactive, and motivating learning environment full of tolerance and enjoyment, and void of over formality and overcorrection.

\section{Acknowledgement}

The researchers highly appreciate the considerable contribution of Dr. Hamdy M. Salem, Associate Prof. of Statistics at the college of commerce, Al-Azhar University, Egypt \& Qassim University, Saudi Arabia. Prof. Salem has volunteered to do all the statistical analyses required for completion of the present research. 


\section{References}

Abahussain, M. O. (2016). Implementing Communicative Language Teaching Method in Saudi Arabia: Challenges Faced by Formative Year Teachers in State Schools. (PhD). University of Stirling, Scotland.

Aida H. Hussein, E., \& Al-Emami, A. (2016). Challenges to Teaching English Literature at the University of Hail: Instructors. Arab World English Journal (AWEJ), 7(4), 125-138. https://doi.org/10.24093/awej/vol7no4.9

Alghanmi, B., \& Shukri, N. (2016). The Relationship between Teachers' Beliefs of Grammar Instruction and Classroom Practices in the Saudi Context. English Language Teaching, 9(7), 70-86. https://doi.org/10.5539/elt.v9n7p70

Alharbi. A. O. (2019). The impact of Saudi Arabian Teachers' Beliefs on their use of L1 or L2 in the Classroom in the Context of Communicative Language Teaching: A Literature Review. Arab World English Journal, 10(4), 344-355. https://doi.org/10.24093/awej/vol10no4.25

Al-Nasser, A. S. (2015). Problems of English language acquisition in Saudi Arabia: An exploratory-cum-remedial study. Theory and Practice in Language Studies, 5(8), 1612-1619. https://doi.org/10.17507/tpls.0508.10

Alrabai, F. (2014). Motivational Practices in English as a Foreign Language Classes in Saudi Arabia: Teachers Beliefs and Learners Perceptions. Arab World English Journal, 5(1). https://doi.org/10.24093/awej/vol10no4.25

Alsalmi, A. A. (2014). Challenges confronting teachers of English language. (Master). Taif University, Taif.

Alshehri, E., \& Etherington, M. (2017). Motivational strategies: the perceptions of EFL teachers and students in the Saudi higher education context. International Journal of English Language Education, 5(2), 46-82. https://doi.org/10.5296/ijele.v5i2.11727

Alsumait, D. S. (2015). The Epistemological Beliefs of Undergraduates towards Information Science, PhD, School of Information Systems, Computing and Mathematics, Brunel University.

Barvarz, R., Nami, Y., \& Ahmadi, S. (2014). The Relationship between The Epistemological Beliefs and Academic Performance, Social and Behavioral sciences, 114, 121-124. https://doi.org/10.1016/j.sbspro.2013.12.670

Batawi, G. H. (2007). Exploring the use of CLT in Saudi Arabia. (Master). American University of Sharjah, Sharjah.

Bobkina, J., \& Dominguez, E. (2014). The use of literature and literary texts in the EFL classroom; Between Consensus and Controversy. International Journal of Applied Linguistics and English Literature, 3(2), 248-260. https://doi.org/10.7575/aiac.ijalel.v.3n.2p.248

Borg, S. (2017). Teachers' beliefs and classroom practices. In The Routledge handbook of language awareness (pp. 93-109): Routledge. https://doi.org/10.4324/9781315676494-5

Cano, F. (2005). Epistemological Beliefs and Approaches to Learning: Their Change Through Secondary School and Their Influence on Academic Performance. British Journal of Educational Psychology, 75(2), 203-221. https://doi.org/10.1348/000709904X22683

Cirakli, M.Z., \& Kilickaya, F. (2011). Literature courses in EFL curriculum: Pre-service language teachers' perceptions. Pegem Ë̆itim ve Öğretim Dergisi, 1(13), 11-15. https://doi.org/10.14527/C1S3M2

Daif-Allah, A., \& Aljumah, F. (2020): Differences in Motivation to Learning English among Saudi University Students. English Language Teaching, 13(2), 63-74. https://doi.org/10.5539/elt.v13n2p63

Daif-Allah, A. (2012). Saudi Students' Beliefs about Foreign Language Learning and Their Relationship to Gender. English Language Teaching, 5(10), 20-33. https://doi.org/10.5539/elt.v5n10p20

El-Helou, H. (2010). Difficulties Facing English Teachers in Teaching Literature in English for Palestine Grade Twelve Textbook. A Master Thesis in Curriculum \& English Teaching Methods, Faculty of Education, The Islamic University - Gaza, Palestine.

Hofer, B. K. (2004). Epistemological understanding as a metacognitive process: Thinking aloud during online searching. Educational Psychologist, 39(1), 43-55. https://doi.org/10.1207/s15326985ep3901_5

Horwitz, E. K. (1988). The beliefs about language learning of beginning university foreign language students. Modern Language Journal, 72, 283-94. https://doi.org/10.1111/j.1540-4781.1988.tb04190.x 
Horwitz, E. (2007). Becoming a language teacher: A practical guide to second language learning and teaching. Hong Kong: Pearson.

Kaşlığlu, Ö., \& Ersin, P. (2018). Pre-service teachers' beliefs about literature integration in English language teaching classrooms. Journal of Language and Linguistic Studies, 14(3), 213-232.

Kaya, S. U. (2018). Integration of Literature in ELT Classes: A Survey of the Attitudes of ELT Students towards the Study of Literature. Baskent University Journal of Education, 5(1), 51-60.

Khatib, M., \& Shakouri, N. (2013). Literature stance in developing critical thinking: A pedagogical look. International Journal of Research Studies in Language Learning, 2(4), 101-108. https://doi.org/10.5861/ijrsll.2012.154

Lieb, M. (2019). Investigating the Relationship Between Cultural Dimensions of Learning and English Language Proficiency. The Electronic Journal for English as a Second Language, 24(2).

Isikli, C., \& Tarakcioglu, A.O. (2017). Investigating problems of English literature teaching to EFL high school students in Turkey with focus on language proficiency. Journal of Language and Linguistic Studies, 13(2), $82-95$.

Marzooghi, R, Fouladchang, M, \& Shemshiri, B. (2008). Gender and Grade Level Differences in Epistemological Beliefs of Iranian Undergraduate Students. Journal of Applied Sciences, 8(24), 4698-4701. https://doi.org/10.3923/jas.2008.4698.4701

Massri, R. (2019). The Perceptions and Beliefs of Saudi Preparatory Year Program Learners Towards Learning English: A Case Study. Arab World English Journal (AWEJ), 10(3), 220-232. https://doi.org/10.24093/awej/vol10no3.15

Ramshe, M. H., Ghazanfari, M., \& Ghonsooly, B. (2019). The Role of Personal Best Goals in EFL Learners' Behavioural, Cognitive, and Emotional Engagement. International Journal of Instruction, 12(1), 1627-1638. https://doi.org/10.29333/iji.2019.121103a

Spataro P, Rossi-Arnaud C, \& Longobardi E. (2018). Are belief-based justifications associated with metalinguistic awareness? A cross-sectional study in school-age children. Child Development, 72, 655-684. https://doi.org/10.1002/icd.2048

Schommer, M., \& Easter, M. (2017). Linking ways of knowing and cognitive flexibility to a critical controversial issue: Guns on campus. International Journal Advances in Social Sciences and Humanities, 5, 38-44. WWW.ijassh.com

Schommer, M., \& Easter, M. (2006). Ways of Knowing and Epistemological Beliefs: Combined effect on $\begin{array}{llll}\text { academic } & \text { performance. }\end{array}$ https://doi.org/10.1080/01443410500341304

Trautwein, U, \& Ludtke, O. (2007). Epistemological Beliefs, School Achievement, and College Major: A Large - Scale Longitudinal Study on the Impact of Certainty Beliefs. Contemporary Educational Psychology, 32, 348-366. https://doi.org/10.1016/j.cedpsych.2005.11.003

Yang, Y.-F. (2018). New language knowledge construction through indirect feedback in web based collaborative $\begin{array}{llll}\text { writing. } & \text { Computer Assisted Language Learning, 31(4), 459-480. }\end{array}$ https://doi.org/10.1080/09588221.2017.1414852

Zaker, A. (2016). Literature and Creativity in an ELT Context. ASIAN TEFL: Journal of Language Teaching and Applied Linguistics, 1(2), 175-186. https://doi.org/10.21462/asiantefl.v1i2.20

Zengin, B., Basal, A., \& Yükselir, C. (2019). Investigation into the Perceptions of English Teachers and Instructors on the Use of Literature in English Language Teaching. Reading Matrix: An International Online Journal, 19(1), 155-166.

\section{Copyrights}

Copyright for this article is retained by the author(s), with first publication rights granted to the journal.

This is an open-access article distributed under the terms and conditions of the Creative Commons Attribution license (http://creativecommons.org/licenses/by/4.0/). 